\title{
ANALISIS KINERJA JARINGAN BERBASISKAN SOFTWARE DEFINITION NETWORK DENGAN PROTOKOL OPENFLOW DI RRI BANDUNG
}

\author{
Nanang Hunaifi ${ }^{1)}$, Rovi Fauzan Akbar ${ }^{2)}$ \\ Program Studi Sistem Informasi ${ }^{1), 2}$, \\ AMIK BSI Surakarta ${ }^{1)}$, Universitas BSI Bandung ${ }^{2)}$ \\ masnaing@gmail.com ${ }^{1)}$, rovifauzan95@gmail.com ${ }^{2)}$
}

\begin{abstract}
ABSTRAK
Jaringan komputer merupakan salah satu yang sangat dibutuhkan saat ini dalam perusahaan ataupun sekolah untuk interkoneksi antara satu sama lainnya, jaringan komputer saat ini masih terpaku pada vendor tertentu karna bersifat close source dengan konfigurasi yang manual jika ada penambahan perangkat, hal ini menyebabkan tidak efisien karena terlalu terpaku pada vendor dan harus mengkonfigurasi setiap perangkat yang ada. Dari permasalahan itu dibentuklah jaringan SDN (Software Definition Network) yang memungkinkan sebuah jaringan komputer tanpa terpaku pada vendor tertentu dengan konfigurasi terpusat pada satu controller sehingga tidak perlu konfigurasi manual jika ada penambahan dan lebih mudah mengontrolnya. Dengan mensimulasikan manajemen jaringan yang fleksibel dan perbedaan kecepatan pertukaran data saat pengiriman data, contoh dari perbedaan jaringan komputer sebelum dan sesudah menggunakan jaringan SDN berbasis protokol OpenFlow dengan hasil $446 \mathrm{Mb}$ lebih cepat saat pertukaran data, maka jaringan $S D N$ dengan protokol OpenFlow merupakan solusi alternatif dari manajemen jaringan dan pertukaran paket data, hal ini diharapkan dapat memecahkan permasalahan yang ada di RRI Bandung.
\end{abstract}

Kata Kunci : Jaringan computer, SDN (Software Definition Network), OpenFlow, Manajemen Jaringan

\section{PENDAHULUAN}

Jaringan untuk saat ini menjadi hal yang sudah mulai diperhatikan, karena menjadi insfrastruktur dalam suatu perusahaan. Banyak pendekatan pendekatan untuk menyesuaikan kinerja dari jaringan agar lebih optimal dan lebih efisien, ada salah satu pendekatan jaringan yang sungguh menarik yaitu jaringan yang dapat diprogram oleh perangkat lunak (Software Definition Network). Seperti yang kita tahu bahwa switch memiliki dua bagian yang disebut dengan bagian control dan bagian data, tugas SDN disini memisahkan antara kontrol dan data dalam jaringan tersebut ${ }^{[1]}$.

OpenFlow bisa menjadi protokol yang baik untuk komunikasi antara switch dan softwarebased controller dalam arsitekture jaringan Software Definition Network hal ini menjadi trobosan baru karena $S D N$ dapat dipercaya mampu menjadi solusi untuk jaringan sekarang yang bersifat sangat kaku, jaringan internet saat ini telah mengalami ossification sehingga jika tetap menggunakan jaringan yang sekarang maka pengembangan akan sangat sulit dilakukan. Jika seperti itu maka Jaringan akan sulit berkembang dan tidak signifikan. Berbeda dengan bagian lain pada perangkat komputer lainnya seperti halnya prosesor dan sistem operasi yang berkembang secara pesat sampai saat ini. apalagi pada saat ini perangkat jaringan yang ada saat ini terlalu bergantung pada vendor dan banyak sekali protokol proprietary, sehingga menyulitkan untuk berhubungan antara perangkat yang berbeda ${ }^{[2]}$.

Berdasarkan uraian diatas dapat dilihat bahwa pada saat ini jaringan komputer ini berperan penting dalam sebuah perusahaan, dan dengan menggunakan jaringan komputer yang dapat diprogram (Software Definition Network) yang menggunakan protocol OpenFlow. Kita bisa dengan mudah berhubungan walau dengan 
berbeda vendor dalam perangkat lunak. Ini akan menambah efek efesiensi bagi perusahaan.

\section{LANDASAN TEORI}

Jaringan komputer adalah dua komputer atau lebih yang saling terhubung dapat saling berkomunikasi dan berbagi sumber daya. Adapun media pengubungnya dapat berupa kabel atau nirkabel yang dapat berupa gelombang radio dan sinar inframerah ${ }^{[3]}$.

Dengan berkembangnya jaringan komputer yang semakin kompleks mengakibatkan rumitnya untuk memanajemen suatu jaringan komputer. Karna semakin banyaknya perangkat jaringan komputer yang saling terhubung, maka dibutuhkan suatu mekanisme monitoring jaringan komputer yang didesain untuk memantau status dari infrastruktur jaringan komputer, memastikan perangkat dalam kondisi baik dan menjaga kestabilan operasional jaringan. maka dibutuhkan NMS (Network Management System). Aplikasi NMS secara umum bekerja menggunakan protokol SNMP (Simple Network Management Protocol), dengan informasi yang diperoleh berupa status up/down device, сри utilization, memory utilization, device type, traffic jaringan dan lain sebagainya ${ }^{[4]}$.

\section{Software Definition Networking}

Software Definition Networking (SDN) adalah arsitektur jaringan yang muncul dimana kontrol jaringan dipisahkan dari forwarding dan secara langsung dapat diprogram. Migrasi kontrol inilah yang sebelumnya terikat erat pada perangkat jaringan individu, yang memungkinkan dapat mengakses ke perangkat komputasi, hal inilah yang mendasari infrastruktur untuk diabstraksikan menjadi aplikasi dan layanan jaringan, yang dapat memperlakukan jaringan sebagai entitas logis atau virtual ${ }^{[1]}$.

Kecerdasan jaringan (secara logis) terpusat pada pengontrol SDN berbasis perangkat lunak, yang digunakan untuk melihat jaringan secara global. Sebagai hasilnya, munculah aplikasi jaringan dan kebijakan mesin sebagai saklar tunggal yang logis. Dengan SDN, perusahaan dan operator dapat mengontrol independen vendor atas keseluruhan jaringan dari satu titik logis, yang sangat menyederhanakan jaringan desain dan operasi. SDN juga sangat menyederhanakan perangkat jaringan diri mereka sendiri, karena mereka tidak perlu lagi memahami dan memproses ribuan standar protokol tetapi hanya menerima instruksi dari Kontrol SDN ${ }^{[1]}$.

\section{Protokol OpenFlow}

OpenFlow yaitu protokol untuk komunikasi antara switch dengan sebuah kontroler yang ada dalam SDN Arsitektur. OpenFlow juga menyediakan protokol terbuka untuk memprogram flowtable di switch dan router yang berbeda, bukan hanya itu OpenFlow juga dapat membuat administrator jaringan berpartisipasi langsung ke dalam lalu lintas data untuk membuat atau meneliti aliran data, dengan ini memungkinkan peneliti dapat mengontrol aliran data mereka sendiri dengan memilih rute paket data yang mereka ikuti dan memproses yang akan diterima oleh mereka ${ }^{[2]}$.

Dengan cara ini, peneliti dapat mencoba protokol routing yang baru, model keamanan, skema pengalamatan, dan bahkan mencari alternative untuk menuju $I P$. Pada jaringan yang sama, lalu lintas produksi yang terisolasi dan diproses dengan cara yang sama seperti hari ini $^{[2]}$.

\section{METODE PENELITIAN}

Metode Penelitian yang digunakan peneliti yaitu melakukan perbandingkan performa jaringan komputer, antara jaringan komputer yang menggunakan jaringan Software Definision Network bassed OpenFlow, dan jaringan komputer yang tidak menggunakan jaringan Software Definision Network, dengan mengirim paket - paket data yang telah disesuaikan bebannya.

\section{Metode Pengumpulan data}

a. Observasi, pada tahap ini Peneliti telah melakukan observasi pada perusahaan RRI Bandung untuk mendapatkan informasi mengenai jenis topologi yang digunakan pada perusahaan tersebut dan perangkat apa saja yang digunakan. 
b. Wawancara, dalam tahap ini peneliti melakukan wawancara secara langsung kepada pihak yang memiliki kewenangan dan pengetahuan mendalam mengenai topologi yang di terapkan pada perusahaan tersebut

c. Studi literature, bahan atau materi penelitian yang dikumpulkan berupa literatur/referensi yang berhubungan dengan penelitian yang akan dilaksanakan.

\section{Hasil dan Pembahasan}

Penelitian ini secara umum terdiri dari 3 langkah utama, yaitu Rancangan Perbandingan dengan Simulasi, Perbandingan Manajemen Jaringan, Pengujian pada kedua Jaringan.

Spesifikasi laptop yang digunakan sebagai berikut :

$$
\begin{aligned}
& \text { - Processor: Intel(R) Core(TM) i3-3110M } \\
& \text { CPU @ 2.40GHz (4 CPUs), 2.4GHz } \\
& \text { - Memory: 4096MB RAM } \\
& \text { - } \text { BIOS: Phoenix BIOS SC-T v2.2 } \\
& \text { P08RBD } \\
& \text { - Card name: Intel(R) HD Graphics } 4000 \\
& \text { - Display Memory: 1696 MB } \\
& \text { - Operating System : Linux UBUNTU } \\
& \text { 16.04 }
\end{aligned}
$$

\subsection{Rancangan Simulasi OpenFlow}

Rancangan dari simulasi ini di buat dengan menggunakan linux sebagai system operasinya, mininet untuk membuat prototype jaringan komputer, virtualbox untuk membuat komputer virtual dan OpenDayLight sebagai protokol OpenFlow yang berperan untuk komunikasi antara perangkat dengan jaringan SDN. sebelum melakukan simulasi ada beberapa perangkat yang penulis gunakan untuk melakukan simulasi yaitu :

1. OpenDayLight yang telah di install dan di simpan pada direktori home dengan nama odl

2. VirtualBox

3. Mininet yang telah terinstall di dalam virtualbox

4. Iperf untuk melihat performa jaringan computer
Adapun tahapan untuk melakukan simulasi ini sebagai berikut :

1. Buka terminal, lalu masukan perintah "cd odl" untuk berpindah direktori

2. Setelah itu maka jalankan OpenDayLight dengan perintah “./bin/karaf" maka akan tampil seperti pada gambar 1

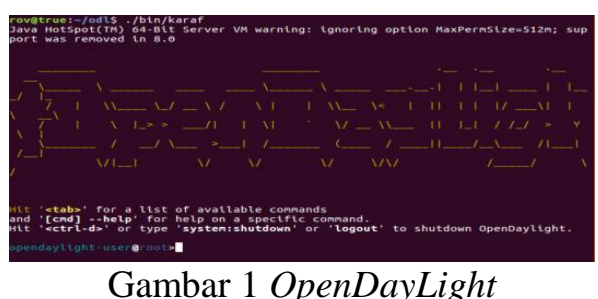

3. Jika muncul seperti gambar di atas maka OpenDayLight telah berjalan, setelah itu coba lihat pada interface OpenDayLight pada browser dengan menuliskan "192.168.56.100:8181/index.html" maka akan muncul seperti gambar 2

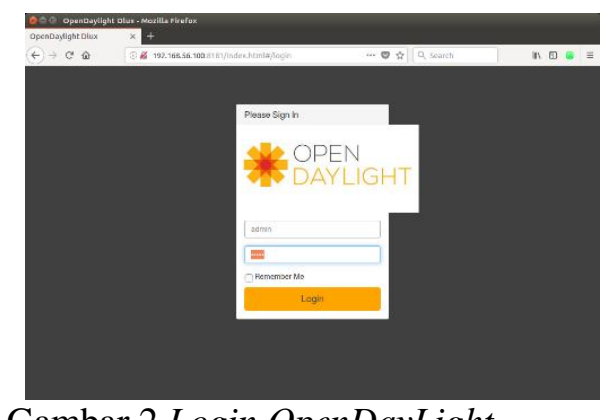

Gambar 2 Login OpenDayLight

4. Gambar 2 merupakan tampilan login dari OpenDaylight, peneliti disini menggunakan IP 192.168.56.100 untuk OpenDaylight, jika OpenDayLight sudah berjalan, lalu kita buat prototype jaringan komputer dengan menggunakan mininet dan virtualbox sebagai virtual komputer yang baru, jadi kita disini seperti memiliki dua komputer dengan operating system yang berbeda. 


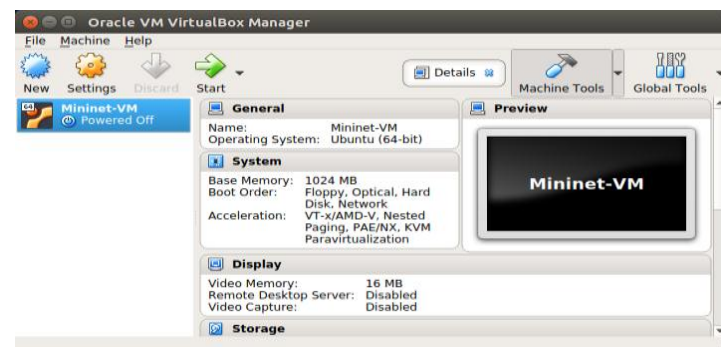

Gambar 3 VirtualBox

5. Jalankan virtualbox yang telah berisi mininet maka akan muncul gambar seperti pada Gambar 3.

6. Lalu kita klik start pada virtualbox untuk menjalankan system operasi yang baru, maka akan muncul seperti 4 .

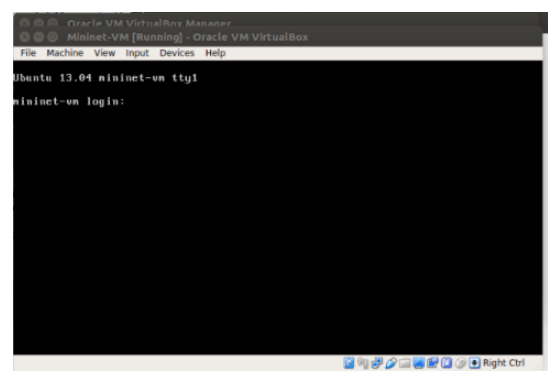

Gambar 4 Mininet Login

7. Gambar diatas adalah tampilan dari mininet yang di buka dengan virtualbox. Agar lebih mudah menkonfigurasi mininet yang ada di virtualbox, peneliti disini akan menggunakan SSH yang ada di linux untuk meremote mininet yang ada di virtualbox, yaitu dengan membuka terminal baru dengan menulis kan perintah seperti pada gambar 5

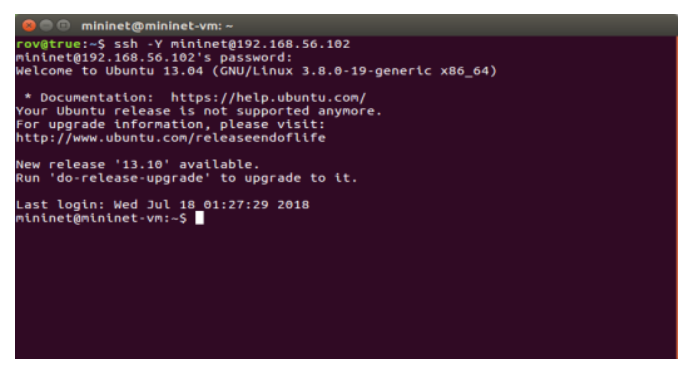

Gambar 5 Mininet dengan SSH

8. Seperti yang terlihat diatas disini peneliti menggunakan IP 192.168.56.102 untuk mininet, setelah kita berhasil masuk kedalam mininet dengan ssh, lalu kita buat prototype jaringan dengan perintah " sudo mn -topo tree, $3-\mathrm{mac} \quad$-controller=remote, $\mathrm{ip}=192.168 .56 .100$, port $=663-$ switch $=$ ovsk ,protocols $=$ OpenFlow13 " maka akan muncul seperti pada gambar 6

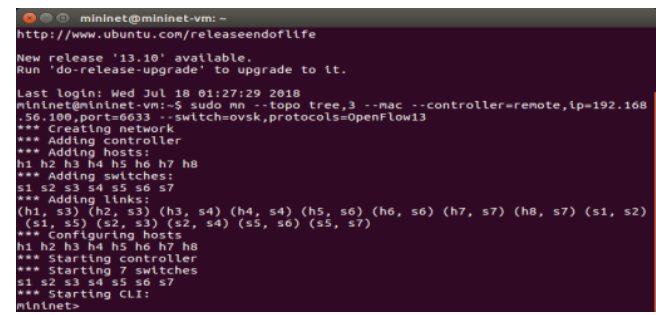

Gambar 6 Pembuatan Topologi pada mininet

9. lalu kita coba lakukan ping untuk melihat konektivitas pada jaringan yang telah di buat, Jika results 0\% Dropped maka tidak ada hambatan pada semua host seperti gambar 7

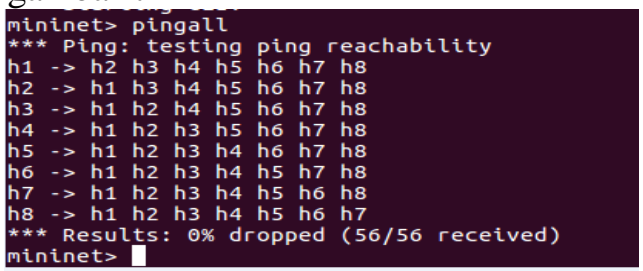

Gambar 7 Check ping pada mininet

\subsection{Manajemen Jaringan}

Manajemen jaringan sebelum menggunakan jaringan SDN. Ketika ada perangkat baru terhubung ke jaringan kita perlu mengkonfigurasinya dulu, kita tidak mengetahui bagaimana alur data itu berjalan, kita tidak tahu paket data apa saja yang rusak atau hilang saat terkirim dan lain sebagainya. Tetapi ketika jaringan komputer SDN dengan protokol OpenFlow ini sudah di terapkan maka semua manajemen jaringan akan terpusat hanya pada satu controller, hal ini sungguh sangat menguntungkan bagi kita, karna kita hanya perlu mengkonfigurasi semuanya lewat satu controller, kita bisa lihat topology apa yang sedang kita gunakan, host apa saja yang terhubung. Disini peneliti menggunakan beberapa fitur yang digunakan untuk meningkatkan manajemen jaringan dan memonitor jaringan, adapun fitur yang peneliti gunakan yaitu:

1. Topology 
Peneliti menggunakan fitur ini untuk melihat seluruh informasi perangkat apa saja yang sedang terhubung kedalam jaringan tersebut, Seperti pada gambar berikut ini

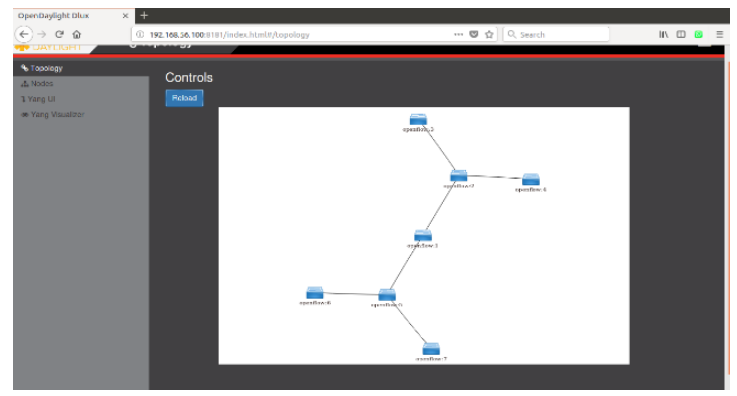

Gambar 8 Topology

Bahkan pada saat perangkat baru yang terhubung mencoba untuk melakukan ping atau pertukaran data, maka rincian informasi perangkat baru tersebut bisa langsung dilihat. Dari mulai port berapa yang menghubungkannya, berapa ip yang digunakannya dan berapa MAC address dari perangkat tersebut seperti pada gambar berikut ini

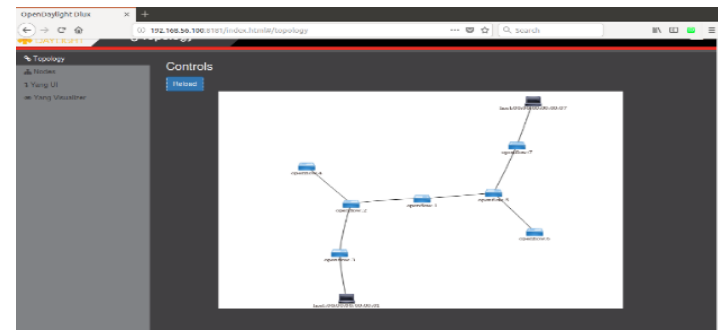

Gambar 9 Topologi test ping 1

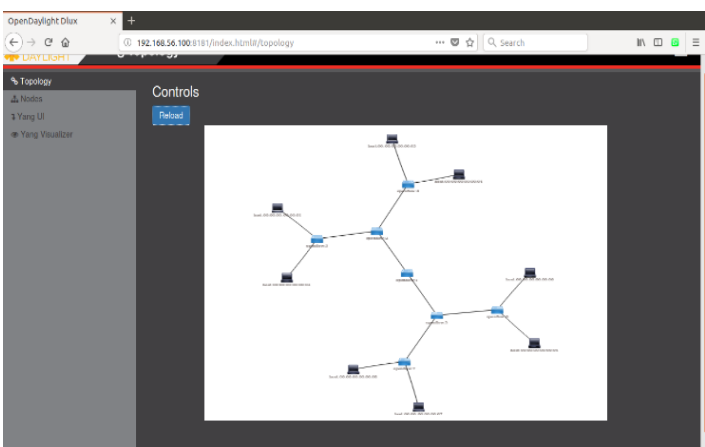

Gambar 10 Topologi test ping all host

Gambar 10 melihatkan seluruh informasi topologi beserta perangkat yang sedang terhubung, tentu ini sudah sangat memudahkan untuk administrator jaringan dalam memonitoring jaringan komputer dan memanajemen jaringan komputer yang ada.

\section{Nodes}

Peneliti menggunakan fitur ini untuk memperlihatkan keseluruhan informasi lebih rinci dari tiap - tiap node yang sedang terhubung, seperti pada gambar 11

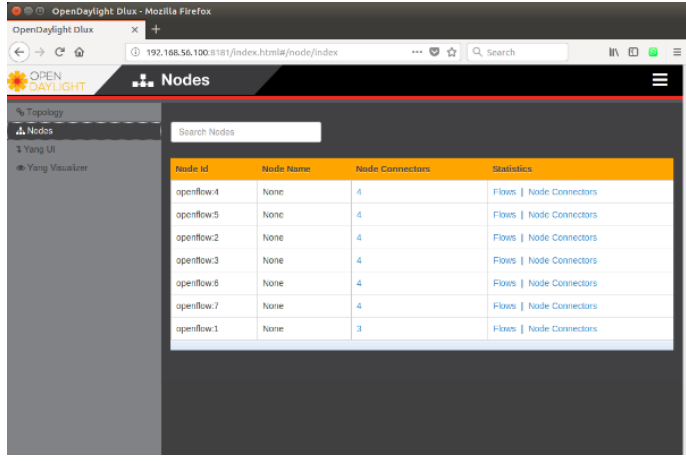

Gambar 11 Nodes

Pada gambar diatas node id berfungsi untuk memberitahu, apa node yang jadi penghubung untuk ke setiap host, node name berfungsi untuk penamaan dari tiap node yang menjadi penghubung ke tiap host, node connectors berfungsi untuk melihat berapa banyak port yang telah digunakan node penghubung, dan untuk statistics berfungsi untuk melihat lebih rinci lagi sekumpulan data informasi dari tiap node penghubung.

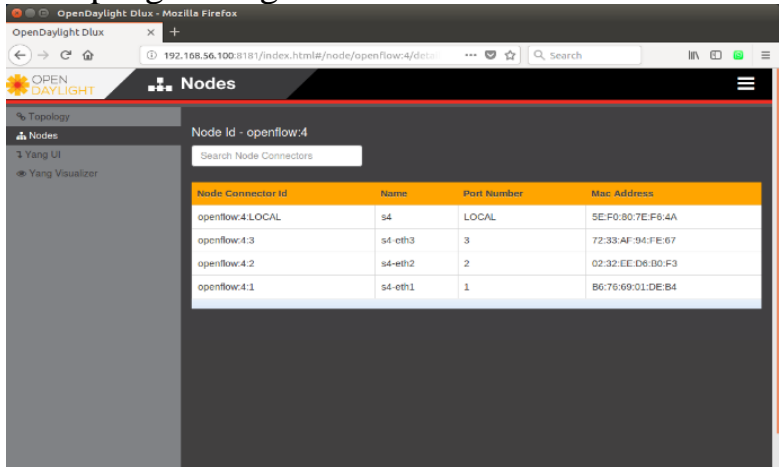

Gambar 12 Node Connector Id

Gambar diatas adalah informasi yang ada dalam node connector, informasi ini tentu membantu administrator jaringan dalam melihat node penghubung tersambung ke perangkat apa saja, menggunakan port apa dan informasi mac 
address dari yang terhubung ke dalam node penghubung.

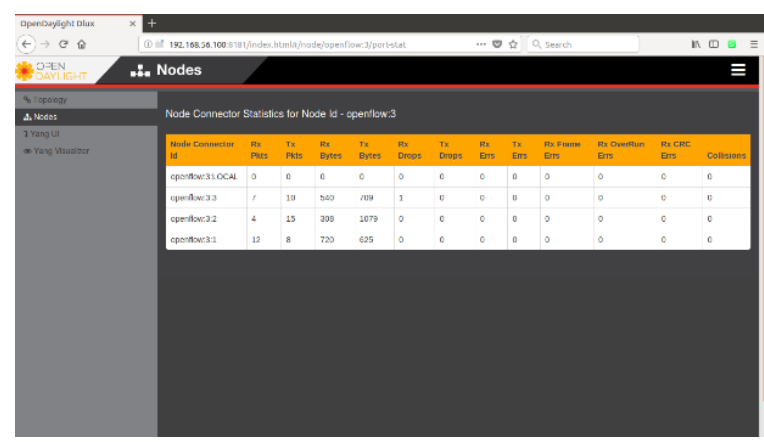

Gambar 13 Node Connector Statistic

Gambar 13 adalah informasi untuk melihat alur dari paket data yang sedang berjalan, tentu informasi ini sangat di butuhkan oleh administrator jaringan untuk melihat informasi mengenai aliran paket data yang sedang berlangsung di dalam node, dengan begini administrator jaringan akan lebih mudah mengetahui beberapa hal yaitu :

a. Jika terjadinya paket data yang rusak, hilang, atau error.

b. Komputer yang sering melakukan pertukaran data.

c. Komputer yang mencoba melakukan flooding kedalam jaringan.

Sebagai bukti bahwa fitur ini dapat melihat informasi dari apa yang telah dijelaskan, peneliti menggunakan tools Iperf untuk mengirimkan paket data sebesar 1GB dengan waktu pengiriman 100 detik, yang akan di kirimkan dari host pertama ke host ke dua seperti pada gambar 14

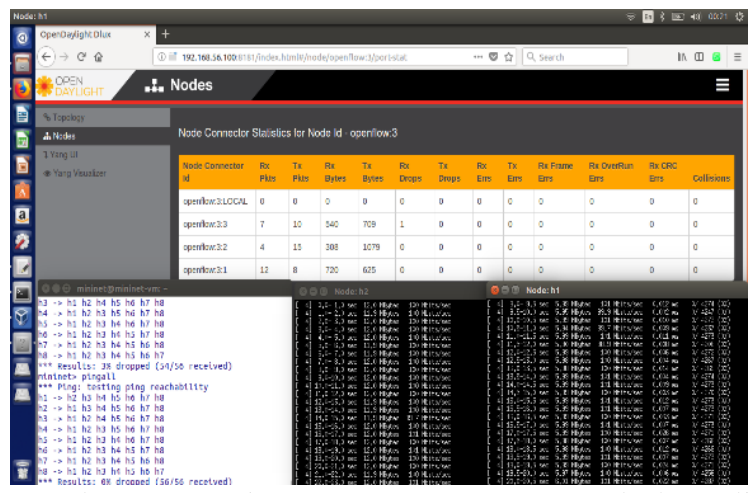

Gambar 14 Node Connector Statistic Sebelum di Banjiri Paket

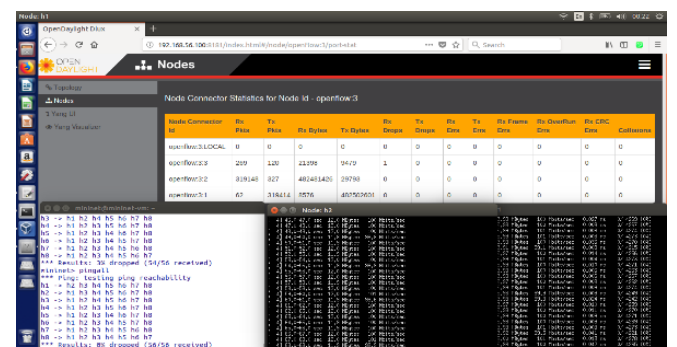

Gambar 15 Node Connector Statistic Sesudah di Banjiri Paket

Gambar 15 adalah bukti fitur ini dapat melihat aliran paket data yang sedang berjalan.

\section{YangUI}

Peneliti menggunakan fitur ini untuk melakukan konfigurasi kepada tiap - tiap node yang menjadi node penghubung untuk mengatur jaringan yang dapat dilihat pada gambar 16

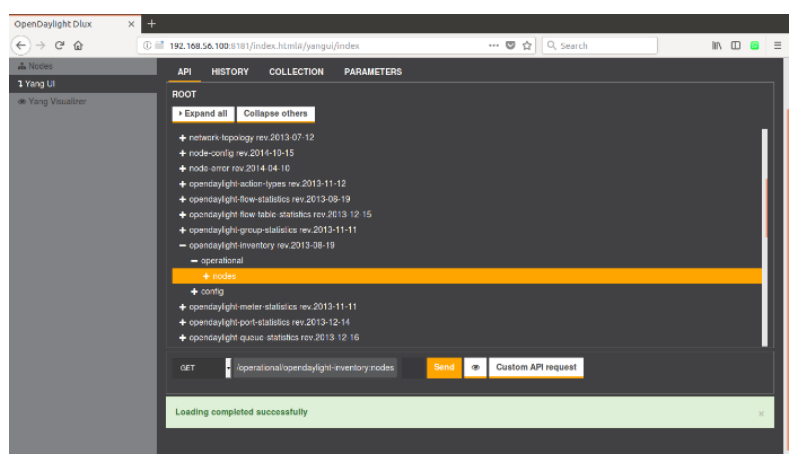

Gambar 16 YangUI

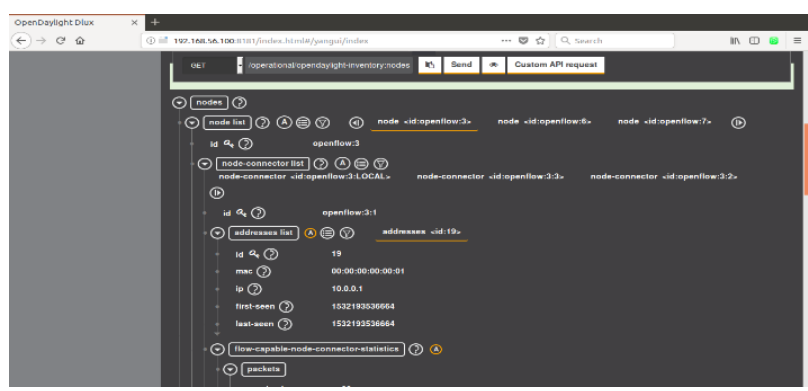

Gambar 17 YangUI Node Setting

Gambar 17 memperlihatkan keseluruhan informasi mengenai hal - hal yang berkaitan dengan node penghubung dan fungsi utama dari fitur ini yaitu untuk mengatur semua configurasi dari tiap node penghubung yang ada dalam jaringan. Dengan begini administrator jaringan hanya fokus mengkonfigurasi tiap node 
penghubung dari satu titik pusat tanpa perlu repot - repot lagi mengkonfigurasi jika ada router atau switch baru yang terhubung. Karna semua konfigurasi sudah terpusat pada satu titik.

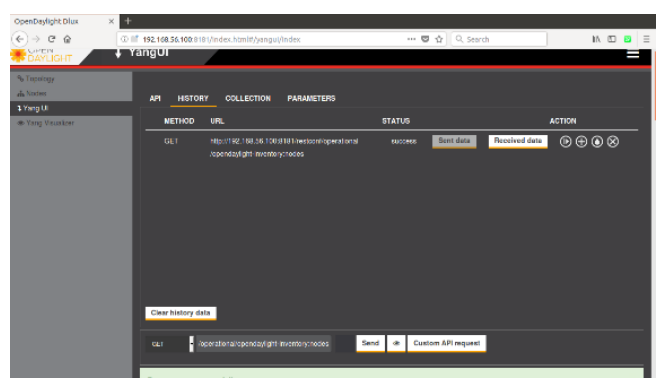

Gambar 18 YangUI History

Gambar 18 memperlihatkan keseluruhan informasi mengenai apa saja riwayat yang telah dilakukan, dengan adanya hal ini tentu ini semakin memudahkan administrator jaringan dalam memanajemen jaringan, karena semua perubahan sistem jaringan komputer atau perubahan konfigurasi jaringan komputer akan tercatat semua kedalam history.

\subsection{Pengujian Jaringan}

Dalam pengujian jaringan komputer, peneliti akan membandingkan antara jaringan komputer yang belum menggunakan jaringan $S D N$ dengan jaringan komputer yang sudah menggunakan jaringan $S D N$ yang menggunakan protocol

OpenFlow. Pada skripsi yang dibuat oleh peneliti ini, pengujian jaringan akan di bagi dua tahapan yaitu pengujian awal dan pengujian akhir

\subsubsection{Pengujian Jaringan Awal}

Pengujian jaringan awal adalah pengujian jaringan dimana pengujian tersebut belum menggunakan jaringan $S D N$, pada tahap ini peneliti sudah menyiapkan 5 skenario dengan menggunakan tools yang telah di install yaitu iperf.

1. Iperf

Iperf adalah salah satu tool untuk mengukur troughput bandwidth dalam sebuah link network, agar bisa dilakukan pengukuran diperlukan Iperf yang terinstall point to point, baik disisi server maupun client. Iperf sendiri bisa digunakan untuk mengukur performance link dari sisi TCP maupun $U D P$.

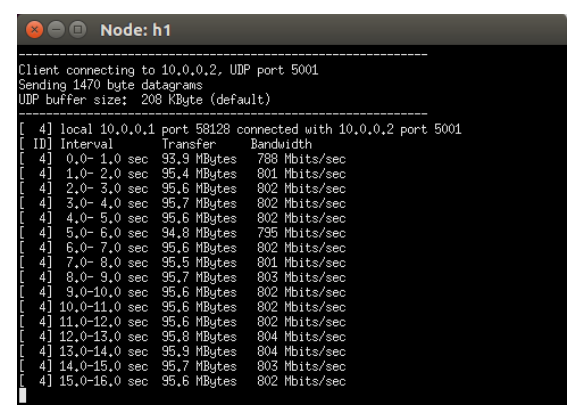

Gambar 19 Iperf sisi client

Gambar diatas adalah perintah untuk mengukur troughput bandwidth yang ada dalam jaringan dalam sisi client.

\section{Keterangan :}

a. $-\mathrm{c}=$ Client atau Host yang mau di lihat performanya

b. 10.0.0.1 = alamat ip yang di check

c. $-\mathrm{u}=$ menggunakan jalur $U D P$ daripada $T C P$

d. $-\mathrm{i}=$ mengatur waktu interval periode interval antar bandwith

e. 1 = waktu interval yg di tentukan, dalam satuan detik

f. $-\mathrm{t}=$ waktu untuk dikirim

g. $100=$ detik yang ditentukan untuk pengiriman data.

h. $-\mathrm{b}=$ bandwith UDP yang dikirim dalam $\mathrm{bit} / \mathrm{sec}$

i. $100 \mathrm{~m}=$ ukuran yang di tentukan untuk bandwith UDP

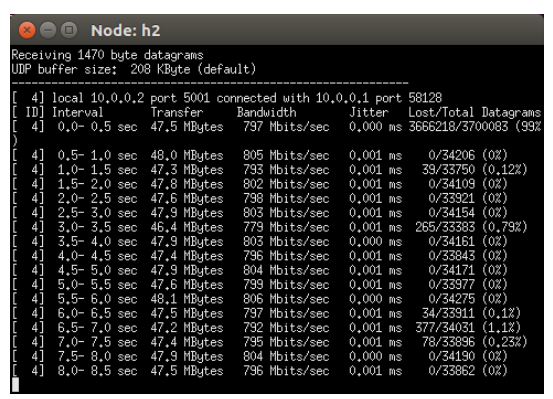

Gambar 20 Iperf sisi server 
Gambar diatas adalah perintah untuk menangkap data yang sedang berjalan dalam sisi server.

Keterangan :

a. $-\mathrm{S}=$ menjalankan iperf dalam mode server

b. $-\mathrm{u}=$ untuk mebaca $U D P$

c. $-\mathrm{i}=$ mengatur interval antara bandwidth, jitter, dan loss data

d. 1 = untuk menulis semua data yang di tangkap

Pada tahap ini peneliti akan mulai membuat skenario untuk melihat performa dari jaringan komputer tanpa menggunakan SDN, dengan gambar sebelah kiri dari sisi client dan gambar sebelah kanan dari sisi server adapun scenario yang akan dibuat sebagai berikut :

a. Skenario pertama dengan bandwidth $100 \mathrm{mb}$

b. Skenario kedua dengan bandwidth $250 \mathrm{mb}$

c. Skenario ketiga dengan bandwidth $500 \mathrm{mb}$

d. Skenario ke empat dengan $750 \mathrm{mb}$

e. Scenario ke lima dengan bandwidth $1000 \mathrm{mb}$

Dari skenario data diatas peneliti membuat tabel untuk menyimpulkan hasil dari jaringan tanpa $S D N$ seperti pada tabel berikut :

Tabel 1 Hasil Pengujian tanpa SDN

\begin{tabular}{|c|c|c|c|c|c|}
\hline Skenario & & Transfer & Bandwidth & Jitter & Lost data \\
\hline 1 & Server & $1.17 \mathrm{~GB}$ & $100 \mathrm{Mb}$ & $0.016 \mathrm{~ms}$ & $0.002 \%$ \\
\cline { 2 - 6 } & Client & $1.17 \mathrm{~GB}$ & $100 \mathrm{Mb}$ & $0.016 \mathrm{~ms}$ & $0.002 \%$ \\
\hline 2 & Server & $2.71 \mathrm{~GB}$ & $246 \mathrm{Mb}$ & $0.006 \mathrm{~ms}$ & $5.3 \%$ \\
\cline { 2 - 6 } & Client & $2.71 \mathrm{~GB}$ & $246 \mathrm{Mb}$ & $0.006 \mathrm{~ms}$ & $5.3 \%$ \\
\hline \multirow{2}{*}{3} & Server & $5.35 \mathrm{~GB}$ & $459 \mathrm{Mb}$ & $0.003 \mathrm{~ms}$ & $0.005 \%$ \\
\cline { 2 - 6 } & Client & $5.35 \mathrm{~GB}$ & $459 \mathrm{Mb}$ & $0.003 \mathrm{~ms}$ & $0.005 \%$ \\
\hline \multirow{2}{*}{4} & Server & $8.89 \mathrm{~GB}$ & $763 \mathrm{Mb}$ & $0.001 \mathrm{~ms}$ & $0.035 \%$ \\
\cline { 2 - 6 } & Client & $8.89 \mathrm{~GB}$ & $763 \mathrm{Mb}$ & $0.001 \mathrm{~ms}$ & $0.035 \%$ \\
\hline \multirow{2}{*}{5} & Server & $7.72 \mathrm{~GB}$ & $680 \mathrm{Mb}$ & $0.001 \mathrm{~ms}$ & $2.9 \%$ \\
\cline { 2 - 6 } & Client & $7.72 \mathrm{~GB}$ & $680 \mathrm{Mb}$ & $0.001 \mathrm{~ms}$ & $2.9 \%$ \\
\hline
\end{tabular}

Keterangan :

a. Transfer

Transfer adalah pengiriman data dari komputer satu ke yang lainnya

b. Bandwidth
Bandwidth adalah kapasitas dari suatu jalur komunikasi yang dipakai untuk mentransfer data dalam hitungan detik

c. Jitter

Jitter adalah variasi waktu dari sinyal periodik atau selisih dari delay paket data

d. Lost Data

Lost Data adalah data yang hilang atau rusak pada saat pertukaran data

\subsubsection{Pengujian Jaringan Akhir}

Pengujian jaringan akhir yaitu pengujian jaringan ketika sudah menggunakan jaringan SDN dengan protokol OpenFlow. Pada tahap ini peneliti sudah menyiapkan 5 skenario sama dengan pengujian sebelumnya.

Pada tahap ini peneliti akan mulai membuat skenario untuk melihat performa dari jaringan komputer yang menggunakan SDN, dengan gambar sebelah kiri dari sisi client dan gambar sebelah kanan dari sisi server adapun scenario yang akan dibuat sebagai berikut :

a. Skenario pertama dengan bandwidth $100 \mathrm{mb}$

b. Skenario kedua dengan bandwidth $250 \mathrm{mb}$

c. Skenario ketiga dengan bandwidth $500 \mathrm{mb}$

d. Skenario ke empat dengan $750 \mathrm{mb}$

e. Scenario ke lima dengan bandwidth $1000 \mathrm{mb}$

Dari skenario data diatas peneliti membuat tabel untuk menyimpulkan hasil dari jaringan dengan $S D N$ seperti pada tabel berikut :

Tabel 2 Hasil Pengujian dengan SDN

\begin{tabular}{|c|c|c|c|c|c|}
\hline Skenario & & Transfer & Bandwidth & Jitter & Lost data \\
\hline 1 & Server & $1.17 \mathrm{~GB}$ & $100 \mathrm{Mb}$ & $0.013 \mathrm{~ms}$ & $0 \%$ \\
\cline { 2 - 6 } & Client & $1.17 \mathrm{~GB}$ & $100 \mathrm{Mb}$ & $0.013 \mathrm{~ms}$ & $0 \%$ \\
\hline 2 & Server & $2.90 \mathrm{~GB}$ & $249 \mathrm{Mb}$ & $0.004 \mathrm{~ms}$ & $0 \%$ \\
\cline { 2 - 6 } & Client & $2.90 \mathrm{~GB}$ & $249 \mathrm{Mb}$ & $0.004 \mathrm{~ms}$ & $0 \%$ \\
\hline 3 & Server & $5.89 \mathrm{~GB}$ & $506 \mathrm{Mb}$ & $0.003 \mathrm{~ms}$ & $0.002 \%$ \\
\cline { 2 - 6 } & Client & $5.89 \mathrm{~GB}$ & $506 \mathrm{Mb}$ & $0.003 \mathrm{~ms}$ & $0.002 \%$ \\
\hline 4 & Server & $8.84 \mathrm{~GB}$ & $760 \mathrm{Mb}$ & $0.001 \mathrm{~ms}$ & $0.036 \%$ \\
\cline { 2 - 6 } & Client & $8.84 \mathrm{~GB}$ & $760 \mathrm{Mb}$ & $0.001 \mathrm{~ms}$ & $0.036 \%$ \\
\hline \multirow{2}{*}{5} & Server & $9.27 \mathrm{~GB}$ & $796 \mathrm{Mb}$ & $0.002 \mathrm{~ms}$ & $0.23 \%$ \\
\cline { 2 - 6 } & Client & $9.27 \mathrm{~GB}$ & $796 \mathrm{Mb}$ & $0.002 \mathrm{~ms}$ & $0.23 \%$ \\
\hline \multirow{2}{*}{ Rata - Rata } & Server & $5.614 \mathrm{~GB}$ & $482.2 \mathrm{Mb}$ & $0.0046 \mathrm{~ms}$ & $0.0536 \%$ \\
\cline { 2 - 6 } & Client & $5.614 \mathrm{~GB}$ & $482.2 \mathrm{Mb}$ & $0.0046 \mathrm{~ms}$ & $0.0536 \%$ \\
\hline
\end{tabular}

Dapat disimpulkan dari pengujian awal dengan jaringan komputer sebelum 
menggunakan jaringan $S D N$ dan pengujian akhir dengan jaringan komputer yang telah menggunakan jaringan $S D N$. bahwa jaringan $S D N$ lebih cepat dalam pertukaran data, dan lebih sedikit mengalami loss data dengan perbandingan hasil rata - rata sebagai berikut :

Tabel 3 Hasil Perbandingan Jaringan

\begin{tabular}{|c|c|c|c|c|c|}
\hline $\begin{array}{c}\text { Jaringan } \\
\text { Komputer }\end{array}$ & & Transfer & Bandwidth & Jitter & Lost data \\
\hline $\begin{array}{c}\text { Sebelum } \\
\text { Menggunakan } \\
\text { SDN }\end{array}$ & Server & $5.168 \mathrm{~GB}$ & $449.6 \mathrm{Mb}$ & $0.0054 \mathrm{~ms}$ & $1.6484 \%$ \\
\cline { 2 - 6 } & Client & $5.168 \mathrm{~GB}$ & $449.6 \mathrm{Mb}$ & $0.0054 \mathrm{~ms}$ & $1.6484 \%$ \\
\hline $\begin{array}{c}\text { Sesudah } \\
\text { Menggunakan } \\
\text { SDN }\end{array}$ & Server & $5.614 \mathrm{~GB}$ & $482.2 \mathrm{Mb}$ & $0.0046 \mathrm{~ms}$ & $0.0536 \%$ \\
\cline { 2 - 6 } & Client & $5.614 \mathrm{~GB}$ & $482.2 \mathrm{Mb}$ & $0.0046 \mathrm{~ms}$ & $0.0536 \%$ \\
\hline $\begin{array}{c}\text { Selisih dari kedua } \\
\text { Jaringan }\end{array}$ & Server & $446 \mathrm{Mb}$ & $32.2 \mathrm{Mb}$ & $0.0008 \mathrm{~ms}$ & $1.5948 \%$ \\
\cline { 2 - 6 } & Client & $446 \mathrm{Mb}$ & $32.2 \mathrm{Mb}$ & $0.008 \mathrm{~ms}$ & $1.5948 \%$ \\
\hline
\end{tabular}

\section{PENUTUP}

Dari beberapa tahapan yang telah dilakukan maka peneliti menyimpulkan sebagai berikut:

1. Dengan menggunakan jaringan SDN yang menggunakan protokol OpenFlow, jaringan komputer jadi lebih mudah di konfigurasi, karena konfigurasinya terpusat pada satu controller.

2. Dengan menggunakan jaringan SDN yang menggunakan protokol OpenFlow, tidak bergantung lagi pada suatu vendor tertentu karna semua perangkat kontrol langsung oleh jaringan SDN.

3. Dengan menggunakan jaringan SDN yang menggunakan protokol OpenFlow, pertukaran data lebih cepat dan kemungkinan untuk terjadi loss data lebih kecil dari yang tidak menggunakan jaringan SDN.

\section{DAFTAR PUSTAKA}

[1] Open Networking Foundation. (2012). Software-defined networking: The new norm for networks. ONF White Paper, 2, 26. https://doi.org/citeulike-articleid: 12475417

[2] Lara, A., Kolasani, A., \& Ramamurthy, B. (2013). Network Innovation using
OpenFlow: A Survey. IEEE Communications Surveys \& Tutorials, PP(99), $1-20$. https://doi.org/10.1109/SURV.2013.081313 .00105

[3] Muktafi, S. (2014). Konsep Jaringan Dasar. [4] Wahyudi, D. (2016). Manajemen Jaring 